\title{
A PESQUISA SOBRE TRAJETÓRIAS ESCOLARES NO BRASIL
}

\author{
INVESTIGACIÓN SOBRE LAS TRAYECTORIAS ESCOLARES EN BRASIL
}

RESEARCH ON SCHOOL TRAJECTORIES IN BRAZIL

\author{
Luciana MASSI ${ }^{1}$ \\ Luci Regina MUZZETI ${ }^{2}$ \\ Darbi Masson SUFICIER ${ }^{3}$
}

RESUMO: O presente trabalho apresenta um balanço com as principais pesquisas realizadas no âmbito da Sociologia da Educação no Brasil com a temática das trajetórias escolares. As pesquisas com a temática das trajetórias escolares estão diretamente relacionadas ao referencial teórico desenvolvido pelo sociólogo francês Pierre Bourdieu. Os trabalhos pesquisados demarcam uma área de estudos dentro da Sociologia da Educação que busca compreender as diferentes trajetórias educacionais e sociais e sua relação com o destino escolar dos alunos. Trata-se de um conjunto de trabalhos empíricos baseados em entrevistas realizadas com estudantes (do ensino fundamental ao superior) e familiares provenientes de diferentes camadas sociais. Depreende-se do conjunto de trabalhos pesquisados que a origem social, o capital cultural dos familiares do aluno e a relação da família com a escola compõem fatores relevantes nas trajetórias de escolarização.

PALAVRAS-CHAVE: Trajetórias escolares. Levantamento bibliográfico. Sociologia da Educação.

RESUMEN: El presente trabajo muestra un balance de las principales investigaciones realizadas en el área de Sociología de la Educación en Brasil con el tema de las trayectorias escolares. Las investigaciones acerca del tema de trayectorias escolares están directamente relacionadas con referencia a la teoría desarrollada por el sociólogo francés Pierre Bourdieu. Los trabajos investigados delimitan un área de estudios dentro de la Sociología de la Educación que busca comprender las diferentes trayectos escolar y social, además de su relación con el entorno escolar de los alumnos. Se trata de un conjunto de trabajos empíricos basados en entrevistas realizadas a estudiantes (de enseñanza fundamental a la educación superior) y familiares que provienen de diferentes clases sociales. Concluiremos con un conjunto de trabajos investigados que da origen social, el capital cultural de los familiares del alumno y la

1 Universidade Estadual Paulista (Unesp), Araraquara - SP - Brasil. Professora Doutora do Departamento de Didática. E-mail: lucianamassi@fclar.unesp.br.

${ }^{2}$ Universidade Estadual Paulista (Unesp), Araraquara - SP - Brasil. Professora Doutora do Departamento de Didática. E-mail: lucirm@fclar.unesp.br.

${ }^{3}$ Universidade Estadual Paulista (Unesp), Araraquara - SP - Brasil. Doutorando em Educação Escolar. E-mail: darbimassonsuficier@hotmail.com. 
relación de la familia con la escuela que componen factores importantes en el trayecto escolar.

PALABRAS CLAVE: Trayectorias escolares. Búsqueda bibliográfica. Sociología de la educación.

ABSTRACT: This study aims to present a balance with the main researches carried out in the scope of Sociology of Education in Brazil with the theme of school trajectories. The researches with the school trajectories theme are directly related to the referential theory developed by the French sociologist Pierre Bourdieu. These studies delimit an area of research, within Sociology of Education, that aims to understand the different school and social trajectories and their relation to the school destination of students. In addition, it is a group of empirical studies based on interviews with students (from elementary school until higher education) and relatives from different social strata. Thus, from the group of studies researched it is possible to deprehend that the social origin, the cultural capital of the student's relatives and their relationship with the school are relevant aspects in the schooling trajectory.

KEY WORDS: School trajectories. Bibliographical survey. Sociology of education.

\section{Introdução}

A Sociologia da Educação no Brasil vem dedicando parte dos seus estudos à análise de trajetórias escolares, tendo como base principal os trabalhos de Pierre Bourdieu e autores contemporâneos, como Bernard Lahire. Em um primeiro momento (Nogueira, 1991, 1995; Romanelli, 1995), esse campo de estudos foi marcado pela preocupação em analisar desigualdades e predizer destinos escolares a partir de dados quantitativos e análises estatísticas, seguindo o modelo das pesquisas de Bourdieu (1998) e de sua parceria com Passeron (BOURDIEU; PASSERON, 1964, 1970). O autor apontava (Bourdieu, 1998) para correlações positivas entre o patrimônio (capital cultural, social e econômico) dos agentes e suas famílias e a trajetória e o desempenho escolar. Ao longo do tempo, as exceções a essas correlações positivas passaram a receber maior enfoque. Atualmente, percebe-se que os autores têm testado tanto a correlação positiva quanto a correlação negativa no nível da análise microssociológica, ou seja, desvelando práticas de pequenos grupos de agentes e procurando por "circunstâncias atenuantes" - expressão elaborada por Lahire (1997) - que justifiquem o sucesso ou insucesso escolar. O foco deixou de ser a constatação das correlações para uma preocupação sobre como elas se constroem, da mesma forma que as exceções. 
[...] compete à reflexão sociológica ir além de uma mera constatação daquilo que seriam as formas com que as estruturas societárias sobredeterminam os indivíduos por elas envolvidos, deduzidas de grandezas e regularidades estatísticas observadas. Certamente porque nem toda a realidade social se deixa apreender neste simplificado esquema, a história dessa disciplina [sociologia] é marcada pela busca de um equacionamento entre esses dois polos, o indivíduo e a sociedade. (D'ÁVILA, 1998, P. 2).

O presente artigo apresenta uma breve síntese das principais contribuições de pesquisas nacionais sobre a análise de trajetórias escolares em alunos provenientes da elite, da camada média e da camada popular, considerando também a existência de subgrupos dentro dessas categorias. Quanto às camadas médias, Romanelli (2000, p. 102), destaca que elas “[...] não constituem um universo social homogêneo, havendo segmentos diversos em seu interior, seja em função de condições socioeconômicas, seja devido ao capital cultural de que dispõem". Essa diversidade terá reflexos no desenvolvimento de práticas escolares específicas para cada subgrupo, como podemos perceber a partir desta breve revisão. Ressaltamos ainda que as pesquisas que originaram os trabalhos objeto deste levantamento foram desenvolvidas com alunos do ensino médio e, em maior número, do ensino superior. Segundo Setton (1999, p. 452), "[...] o ensino superior seria o espaço por excelência para se medir as vantagens ou desvantagens culturais acumuladas nas trajetórias socioacadêmicas dos alunos" (SETTON, 1999, p. 452).

\section{Trajetórias escolares de alunos das elites}

Prado (2000), a partir de um levantamento preliminar de dados quantitativos, analisa uma estratégia educativa específica das elites: os intercâmbios culturais. O autor sugere que essa prática estaria associada a uma aprendizagem mais distintiva das línguas estrangeiras, diante da proliferação de escolas de idiomas, e ressalta que essa estratégia é antiga, mas atualmente atinge níveis de escolarização anteriores ao universitário.

O trabalho de Nogueira (2002) destaca que a escolarização das elites é um campo de estudos muito recente e apresenta questões em aberto. A influência do privilégio econômico nos destinos escolares ainda não é compreendida, ao contrário da riqueza cultural, cujos efeitos sobre a trajetória escolar já foram amplamente estudados. Nesse trabalho, a autora analisa, por meio de entrevistas com os alunos e suas mães, as estratégias de escolarização de 25 famílias de empresários de pequeno e médio porte de 
Belo Horizonte, com filhos cursando o nível superior. Nogueira (2002) observou um distanciamento entre essas trajetórias e aquelas de "excelência escolar", marcado por um desempenho inferior, a partir de indicadores clássicos: fluxo, velocidade, longevidade, opções, carreiras e instituições escolares, distinções acadêmicas. Esses alunos ingressam muito cedo no mercado de trabalho, especificamente no universo empresarial, e não reconhecem os saberes da escola como úteis ou práticos. Ainda sobre a temática, a autora destaca em outro artigo que seus pais "não apostam todas as fichas na escola" (NOGUEIRA, 2004, p. 142), por não acreditarem na sua capacidade de preparação para o mundo dos negócios. A escola serviria apenas como um espaço para que o aluno desenvolva sua rede de sociabilidade ou seu capital social, uma vez que esse é o critério preponderante na escolha do estabelecimento de ensino. Associa-se a esses fatores a baixa escolaridade dos pais, que não conseguem impor aos alunos o amor pelo estudo, embora exortem ao empenho escolar; essas famílias empregam estratégias de tipo econômico, como prepará-los para a sucessão do negócio desde muito jovens e associá-los à empresa paterna ou a um negócio próprio durante seu período de formação.

Nogueira e Pereira (2010, p. 17) analisaram a escolha pelo curso de Pedagogia entre alunas de "perfil social e escolar mais elevado". Eles realizaram entrevistas semidiretivas com 8 alunas dentro desse perfil e as agruparam em 4 pares a partir de traços comuns nas suas escolhas pelo curso, considerado pouco prestigiado: no subgrupo 1 a Pedagogia surgiu como saída para crise pessoal e profissional; no subgrupo 2 o curso representava a realização adiada de um gosto socialmente reprimido; no subgrupo 3 a opção pela Pedagogia foi uma decisão mais precoce; e no subgrupo 4 parecem se enquadrar os casos de "escolha pelo possível", associados à ideia da “causalidade do provável”, proposta por Bourdieu (1998). A preocupação dos autores era compreender a relação entre o gosto e as escolhas em meio a condicionantes sociais. A análise dos 8 casos levou os autores a apontarem para a importância da:

[...] relativização das explicações sociológicas sobre a escolha do curso superior, que tendem a considerar o gosto ou as preferências individuais simplesmente como frutos de uma adaptação de agentes a sua condição social passada ou a sua situação atual de ação. (NOGUEIRA, 2010, p. 15).

Vale ressaltar que, apesar da existência de poucos trabalhos sobre a trajetória de escolarização das elites no Brasil, em 2002 foi publicado o livro A escolarização das 
elites, organizado por Almeida e Nogueira (2002), o qual apresenta um panorama sobre o tema com pesquisas de autores brasileiros (Nogueira, Canêdo, dentre outros) e estrangeiros (Pinçon, Pinçon-Charlot, Saint Martin, dentre outros). Trata-se de um conjunto de pesquisas focadas principalmente nas formas de socialização, nos processos escolares e na escolha da instituição escolar realizados pelas elites de localidades situadas no Brasil, França, Suíça, Rússia, Inglaterra, Suécia e Estados Unidos.

\section{Trajetórias escolares de alunos das camadas médias}

Em outro grupo de trabalhos analisamos aqueles preocupados com as camadas médias. Nogueira (1995) defende a relevância desse grupo de estudos a partir de três argumentos: o fato de que existem poucos trabalhos (quase ausência) sobre as práticas educativas das classes médias brasileiras; a importância de analisar estratégias e trajetórias escolares de uma classe em relação à outra; o fato de que essas famílias atribuem à escola um lugar central em seus projetos de futuro. Ela ainda traz definições sobre o que seriam as classes médias, apoiada em parâmetros econômicos, e conclui definindo seu grupo de estudo, nessa pesquisa, nas frações superiores da classe média, que "[...] se caracterizam pela posse de um certo capital cultural e por ocupações de nível superior, e que são mais ou menos equipadas em capital econômico e social" (NOGUEIRA, 1995, p. 14). Posteriormente, a autora apresenta, com base em outras pesquisas além da sua, algumas características da relação que as famílias desse grupo estabelecem com a escola: aderem intensamente a seus valores, por enxergar na escola a possibilidade de mobilidade social; praticam um investimento escolar de energia e tempo que nem sempre se traduz em gastos pecuniários; acompanham cuidadosamente a escolaridade dos filhos dentro e fora da escola; acreditam na necessidade de um trabalho conjunto entre pais e professores, cuja relação é descontraída e centrada em aspectos pedagógicos; detém um amplo sistema de informações sobre o sistema escolar, apoiada em uma rede de contatos com os outros pais de alunos - a posse desse capital favorece a escolha pelo estabelecimento de ensino; estimulam atividades extraescolares que implicam em exercício e assiduidade, promovendo aprendizagem sobre o uso do tempo; transmitem o gosto pela leitura a partir de suas próprias práticas.

Quase 20 anos depois, Nogueira (2010) revisou esse artigo sob a perspectiva da renovação teórica da problemática da relação classes médias e escola, considerando a contribuição de diversas pesquisas francesas e anglo-saxônicas. Inicialmente ela destaca 
que esse campo tem cada vez mais legitimidade embora não tenha perdido seu caráter marginal. Uma explicação de natureza epistemológica para isso seria o fato de que o sociólogo geralmente opera uma autoanálise ao trabalhar com as classes médias. Quanto à definição da classe média a autora reconhece que continua sendo problemática, mas que o seu forte processo de expansão fez com que 52\% da população brasileira pudesse ser enquadrada nessa categoria, segundo dados do Instituto de Pesquisa Econômica Aplicada (IPEA) do ano de 2008. Em relação à divisão interna desse grupo, a autora apresenta diversas formas de diferenciação, bem como o posicionamento de autores contra o estabelecimento de demarcações claras entre esses subgrupos. Com relação à educação, a autora destaca: a procura por escolas particulares e a diferenciação dessa rede de ensino diante da sua expansão; a reivindicação das famílias pelo tipo de formação, estabelecimento de ensino e até sala de aula, diante do acirramento da concorrência escolar e exigência de percursos mais longos, criando um mercado escolar mesmo nas escolas públicas; o aumento da "capacidade estratégica" da classe média e "sofisticação" de investimentos e estratégias educacionais, pois a escola continua fortemente integrada a uma estratégia de reprodução social; o apelo à internacionalização da formação e da carreira escolar dos filhos com variação de intensidade segundo a fração de classe e país de origem. Nogueira (2010) destaca que essas estratégias configurariam uma passagem da meritocracia para a "parentocracia" exemplificada pelo investimento das famílias brasileiras em cursinhos pré-vestibulares na qual a riqueza e os desejos dos pais são mais importantes do que a capacidade e o esforço do aluno. Além disso, a autora destaca que as pesquisas atuais passam a enfocar o "sentido que os atores conferem a essas condutas" e "como eles as vivenciam" (NOGUEIRA, 2010, p. 225). Esse novo olhar permite que as estratégias educativas das classes médias também sejam interpretadas como fonte de dúvidas, tensões e ansiedades por parte dos pais.

Romanelli (1995) investigou o significado da educação superior para duas gerações de famílias da camada média. Nesse texto o autor aponta para diferentes estratos ou segmentos das camadas médias, em função de determinantes econômicos e simbólicos, e destaca a existência de diferentes categorias de universitários, segundo sua relação com a família e o trabalho: o "estudante em tempo integral" é totalmente sustentado pela família; o "estudante-trabalhador" é mantido por seus pais em termos de habitação e alimentação e trabalha para custear outras despesas; e o "trabalhadorestudante" trabalha para se manter e colabora para compor o orçamento doméstico. Em 
sua pesquisa o autor trabalhou com dados anteriores, de casais que frequentaram a universidade no final da década de 60 e início da década de 70, e dados mais recentes, coletados junto a 10 "estudantes em tempo integral” dos cursos de Ciências Biológicas, Psicologia e Química da Faculdade de Filosofia, Ciências e Letras da USP/Ribeirão Preto. Ele observou na segunda geração uma ausência de projetos coletivos e utopia, que marcavam a primeira geração, bem como uma "descrença muito grande na política e economia do País", que não impedem a existência de projetos familiares e a esperança de um futuro melhor (Romanelli, 1995, p. 472).

Almeida (2000) investigou o papel da educação como estratégia de inserção nas camadas intelectualizadas por famílias de grupos médios, possuidoras de credenciais escolares relativamente baixos e residentes em bairro pouco nobre da cidade de São Paulo. Para isso, desenvolveu um estudo em colégio privado, destacado por sua capacidade de preparar alunos para as carreiras mais seletivas da USP e que exige pesados investimentos financeiros e de tempo nos estudos. Assim, a autora questionou o que leva jovens de 15 anos a submeterem-se de boa vontade a condições de trabalho altamente rígidas e controle de aspectos considerados pessoais de sua existência. Sua hipótese é que a justificativa para a adesão a esses valores se apoie em dois pilares: o sentido ascendente da trajetória social das famílias e a posição dominada no espaço social da cidade de São Paulo. Nesse sentido, destaca que as disposições que os alunos apresentam em relação à escola são tributárias da história de toda sua família e da relação dele com essa história.

Posteriormente, Romanelli (2000) analisou a trajetória de 10 estudantes de uma universidade particular da cidade de Ribeirão Preto, classificados como "estudantestrabalhadores". O autor identifica que esses estudantes percorreram o que Souza (19901991) denominou "circuito vicioso", ou seja, o aluno frequentou o ensino fundamental e médio em escolas públicas e o ensino superior em universidade particular; o contrário seriam os "circuitos virtuosos". Para eles e seus pais, o trabalho não é considerado incompatível com a continuidade dos estudos e representa uma forma de reduzir os gastos parentais com o aluno. $\mathrm{O}$ autor discute uma série de particularidades desse grupo que se mostrou semelhante à que encontramos em trabalho anterior, desenvolvido por Massi e colaboradores (2009, 2010), sobre estudantes do curso de Química de uma universidade particular paulista. Romanelli destaca que o acesso ao ensino superior deve ser contrastado com a avaliação que ele pode agregar à sua força de trabalho, pois o capital escolar obtido em uma Instituição de pouco prestígio apenas habilita o portador 
do diploma a "trabalhar mais", ampliando a jornada de trabalho, e não a "ganhar mais" (ROMANELLI, 2000, p. 121). Isso também se dá em função dos cursos escolhidos, devido a limitações da própria história familiar. Quanto à família, apesar dos jovens alegarem que ela não influencia nas suas escolhas, os pais incentivam e estimulam, mesmo que de modo indireto, o ingresso no ensino superior.

Ainda dentro dos estudos sobre a camada média, Nogueira (2000) analisou as trajetórias escolares de 37 estudantes da Universidade Federal de Minas Gerais (UFMG) cujos pais eram professores do ensino superior e pesquisadores, partindo do pressuposto que essa configuração potencializaria ao máximo a atuação do capital cultural. De modo geral, as trajetórias desses alunos são marcadas por fluência, linearidade e continuidade. De acordo com a classificação de Souza (1990-1991), a autora percebeu que os alunos fizeram o "circuito virtuoso". Nos poucos casos em que os alunos frequentaram a escola pública, eram escolas de aplicação da UFMG, reconhecidas pela sua qualidade. Para esse grupo o ensino superior se apresenta "com a força de uma quase "evidência" (NOGUEIRA, 2000, p. 132). Apesar disso foi observado o uso de duas estratégias para garantir o ingresso nessa instituição de ensino superior pública: a realização do vestibular como treineiro e a frequência ao curso pré-vestibular. Porém, a autora observa que o curso pré-vestibular é diferenciado, oferecendo aulas particulares de algumas matérias e frequentado por períodos inferiores a 6 meses. Depois do ingresso no ensino superior os alunos participam de atividades extracurriculares, estimulados por seus pais, para melhorar seu currículo, como é característico de famílias culturalmente privilegiadas, denotando um desprezo pelo utilitarismo. Além disso, poucos trabalham; aqueles que o fazem se dedicam em caráter esporádico e ligado ao conhecimento (como dar aulas particulares), e também realizam parte de seus estudos no exterior. A autora ressalta que a especificidade do grupo estudado é o benefício de um capital que não se reduz ao cultural, embora esteja ligado a ele, pois enquanto produtores do saber e de sua relação profissionalizada, esses pais podem investir esse capital lucrativamente na escolaridade dos filhos. Retomando a noção de herança encontrada em Bourdieu (1998), a autora afirma ainda que, para converter o capital cultural familiar em pessoal, é necessário a mobilização tanto do jovem quanto dos pais.

Lelis (2005) analisou o sentido da experiência escolar para alunos da camada média de uma instituição privada confessional da zona sul do Rio de Janeiro, enfocando: as condições de produção e expressão do ofício do aluno; a caracterização socioeconômica das famílias; a trajetória escolar dos alunos; práticas culturais e de 
lazer; e o papel do estudo na vida desses estudantes. Ela observou o ambiente escolar, as aulas e outros eventos, entrevistou coordenadores e professores e aplicou um questionário para 30 alunos da oitava série do ensino fundamental. A Instituição analisada passa por uma crise com relação à sua qualidade e, pelo que podemos depreender das entrevistas, atende alunos que não parecem ter uma relação positiva com a escola. Os alunos apresentam um perfil semelhante ao encontrado nos outros estudos sobre camadas médias aqui mencionados: prole reduzida, trajetória contínua (sem reprovações), estudos no exterior, entre outros. Porém, seus pais parecem valorizar a escola apenas no âmbito de um discurso que não se reflete em práticas de acompanhamento dos alunos. Assim, a autora destaca que a pesquisa com as camadas médias deve levar em consideração uma pluralidade de estilos de vida e gostos, que extrapolam seus volumes de capital econômico e cultural.

\section{Trajetórias escolares de alunos das camadas populares}

Um terceiro grupo de estudos se ocupou das camadas populares. D’Ávila (1998) analisou 34 famílias pertencentes a estratos médio-baixos e baixos de Vitória (ES), cujos filhos cursavam a oitava série, tendo alta performance escolar - definida a partir de atas de notas finais - e que, posteriormente, foram admitidos na Escola Técnica Federal local. O autor entrevistou os pais dos alunos, buscando perceber as estratégias de investimento educacional desse grupo. Ele destacou o papel de fatores como o gosto, a responsabilidade e a autonomia para analisar a relação entre custo/risco/benefíciomais-útil que observou nas famílias quanto a seus investimentos escolares, reconhecendo a importância da escola no desenvolvimento das trajetórias. Essa presença da escola se dá tanto com relação aos julgamentos positivos, que estimulam a continuidade dos estudos e o encaminhamento para escolas melhores como a escola técnica, quanto com relação à qualidade do ensino ao qual os estudantes de meios pouco favorecidos têm acesso, promovendo a desigualdade. Ele também destaca que a expectativa de continuidade dos estudos não aparece como estratégia de investimento por completo desde o início da escolaridade. Essa percepção também foi notada por Vianna (2000).

Zago (2000) acompanhou durante intervalos de tempo a situação escolar de 16 famílias, com filhos cursando o ensino fundamental, residentes da periferia de Florianópolis. Ela entrevistou todos os pais e parte dos filhos e aplicou um questionário 
para levantamento de dados socioeconômicos e demográficos. A autora destaca que não existem regras gerais para definir a condição de escolaridade de uma classe, pois em uma mesma família encontrou variações nos percursos escolares e nas práticas adotadas. Assim, afirma que as condições desfavoráveis desse grupo tomadas como um dado isolado não são suficientes para explicar o sucesso ou fracasso escolar. Ela destaca os resultados escolares favoráveis e a consequente aproximação com o universo escolar como "circunstâncias atenuantes" para o sucesso escolar. Destaca ainda sobre as contradições que esses jovens vivem entre o mundo do trabalho, para o qual são encaminhados precocemente, e o mundo escolar.

A longevidade escolar, entendida como chegada ao nível superior, em camadas populares foi foco do estudo de Viana (2000) que envolveu 7 estudantes de graduação ou pós-graduação de diferentes instituições de ensino superior de Minas Gerais e suas famílias. Viana (2000) aponta para uma grande heterogeneidade das configurações familiares e de situações de longevidade escolar, sendo que, em cada caso, um dos aspectos estudados tinha maior ênfase: oportunidades de acesso a boas escolas; recusa da perspectiva profissional do pai; inserção em grupos de amigos da classe média; suportes familiares; figura da mãe; afinidade com a cultura legítima; desejo de emancipação de origens rurais. Ela também destaca algumas semelhanças entre os casos que corroboram tendências mais gerais de trajetórias escolares em meio popular, tais como: desempenho escolar bom e regular nas séries iniciais seguidos de períodos acidentados; vestibular como grande obstáculo, contornado pela utilização frequente do cursinho; dificuldade de conciliação entre trabalho e estudo; frequência à escola pública. Para ela, assim como para Nogueira (2000), a família participa da construção do sucesso escolar, mas o aluno é o grande responsável. A escola atua de forma indireta, nos bastidores desse processo.

Piotto (2008) foca seu estudo nos jovens provenientes de camadas populares que ingressaram no ensino superior. Ela revisa outras pesquisas sobre esse grupo, preocupadas tanto com o acesso quanto com a permanência do aluno nesse nível de ensino, e analisa uma entrevista realizada com aluno da camada popular que frequenta um curso superior de alta seletividade - Psicologia - na Universidade de São Paulo. Ela destaca a centralidade da família em percursos alongados de alunos da camada popular e questiona alguns significados atribuídos à longevidade escolar desse grupo, como conformismo, sofrimento e ruptura cultural. No trabalho de Viana (2000), encontramos referências a esses sentimentos, mas não acreditamos que elas apontem apenas aspectos 
negativos. Viana (2000) utiliza o conceito de "tríplice autorização" de Rochex (1995) para discutir os problemas de continuidade, rupturas e ambivalências vividos pelos alunos ao se afastarem cultural e socialmente de seus pais: inicialmente o filho autorizase a deixar a família; depois os pais autorizam o filho a se emancipar; por fim há um reconhecimento recíproco entre pais e filhos de que a "história do outro é legítima sem ser sua" (VIANA, 2000, p. 56). Dialogando com esses resultados, Piotto (2008) afirma que, em sua pesquisa, muitas vezes a entrada na universidade traz mudanças positivas, como o orgulho e a alegria dos pais, alterações de hábitos familiares, estabelecimento de outro tipo de relação e maior aceitação de determinados comportamentos. Ela aponta para a necessidade de investigar a participação da escola nos percursos alongados e sentidos além do sofrimento associado ao acesso e permanência no ensino superior.

Estudantes da camada popular que atingiram o nível superior também foram enfoque da pesquisa de Portes (2000). Porém, o autor analisou aqueles que frequentaram cursos altamente seletivos e supervalorizados socialmente. Segundo ele, um dado geral sobre os alunos era que eles se aproximavam do que Bourdieu (1998) denominou estudantes super-selecionados. Portes (2000) destaca que esses alunos tiveram uma trajetória escolar brilhante e sempre foram os melhores alunos da sua turma. Assim como Muzzeti (2010) se referiu a alunas da camada popular que atingiram o nível superior em universidade pública como "eleitas", Portes observa que esses alunos representam improbabilidades estatísticas em seu meio. Para o autor, no contexto dessa improbabilidade deve-se desvelar e admitir o enorme esforço empreendido pelas famílias, que é legitimado a partir de "circunstâncias atenuantes", como: a ordem moral doméstica; a atenção para com o trabalho escolar do filho; o esforço para compreender e apoiar o filho; a presença do outro na vida do estudante; a eterna aproximação dos professores; a busca da ajuda material; e a existência e importância de um duradouro grupo de apoio construído no interior do estabelecimento escolar. Em sua análise, Portes (2000) apresenta um ponto divergente entre sua pesquisa e a de D’Ávila (1998), cujos familiares analisados pareciam guiar suas ações por uma equação custo-risco-benefício-mais-útil. As mães dos alunos analisados por Portes (2000) pareciam entender o trabalho escolar como uma obrigação cotidiana necessária para a formação do filho. $\mathrm{O}$ autor aponta ainda para um planejamento precário e um horizonte temporal bastante curto, decorrente da frágil situação material da família que se desestabiliza frequentemente frente às exigências escolares; bem como, para o fato de que as "circunstâncias atenuantes" não têm efeito importante de forma isolada, assim 
como Zago (2000) comentou ao se referir às condições desfavoráveis da camada popular.

Posteriormente, em sua tese de doutorado, Portes (2001) analisa em detalhes as trajetórias escolares desses mesmos 5 alunos da camada popular que frequentam cursos altamente seletivos da UFMG. Ele faz um estudo histórico da inserção da camada popular nas Academias Jurídicas de Olinda/Recife e São Paulo e trabalha com dados da fundação da UFMG que tem programas específicos de assistência a esses alunos. Assim, percebe que "um forte elo de ligação entre os estudantes pobres, nos diferentes períodos, é o constrangimento econômico ao qual eles veem sendo submetidos historicamente" (PORTES, 2001, p. 255). Além desse, destaca outros "efeitos de durabilidade e permanência" ao se referir a fenômenos sociais que se prolongam ao longo do tempo, adquirindo a aparência de "normais", como a diferença de idade desses alunos em relação aos demais da turma e o bom desempenho escolar no decorrer de suas trajetórias, incluindo o ensino superior. O autor destaca ainda a importância da família na concretização dessas trajetórias, como já apresentamos anteriormente.

Zago (2006) também analisa trajetórias de 27 estudantes da camada popular que frequentam o ensino superior em cursos de maior e menor prestígio, em um contexto que, segundo ela, vem sendo denominado como "longevidade escolar", casos "atípicos" ou "trajetórias excepcionais", no qual o desvendamento de práticas familiares e individuais, capazes de gerar essas exceções, seria tão ou mais importante que a constatação da desigualdade. Assim como Portes $(2000 ; 2001)$, a autora ressalta que a chegada ao ensino superior não é natural, até mesmo pela falta de "capital informacional" dos agentes dessa classe sobre o sistema escolar, e que a aprovação no vestibular é entendida como "sorte". Depois do ingresso os alunos relatam dificuldades de formação escolar e de manutenção financeira no curso, em alguns casos facilitada pela formação de um "pé-de-meia", resultado de trabalhos anteriores - assim como relatado na pesquisa de Portes (2000), e em outros pelo recebimento de uma bolsa de estudos, voltada para pesquisa ou extensão universitária. A sensação de pertencimento/não-pertencimento desses alunos em relação aos outros alunos de sua turma varia em função do curso estudado.

Santos e Dias (2013) analisaram a trajetória de quatro professoras (duas com 50 anos e duas com cerca de 30 anos) na cidade de Belo Horizonte. Provenientes das camadas populares, as quatro professoras buscam, por meio de estratégias educacionais, aumentar a longevidade escolar dos filhos e transmitir-lhes o capital cultural adquirido 
por meio de suas próprias trajetórias de escolarização. Outro ponto ressaltado pelos pesquisadores é de que, a escolha da profissão, deve-se à precocidade do exercício profissional obtido com a formação na modalidade normal de nível médio (o magistério), bem como pelo desejo de seus pais (para 3 professoras), em ter uma filha professora. Por sua vez, Oliveira e Alvarenga (2014) analisaram a trajetória de escolarização de 9 jovens entre 15 e 18 anos residentes no Complexo do Salgueiro, no Rio de Janeiro. Entre os jovens, 3 abandonaram a escola no ensino fundamental e apenas dois haviam ingressado no ensino médio, perfazendo, para os autores, a "taxa de distorção idade-série" ser de $100 \%$ no grupo pesquisado. Baseados em Bourdieu, os autores concluem que a exclusão "ocorre no interior do sistema de ensino" (Oliveira e Alvarenga, 2014, p. 11). Todos os jovens do grupo possuem famílias com baixa ou nenhuma escolaridade, o que corrobora os resultados obtidos nas outras pesquisas citadas nesta camada.

A pesquisa realizada por Oliveira e Portes (2014) possui a peculiaridade de analisar a trajetória de um único entrevistado, um jovem proveniente das camadas populares que ingressou em um curso de prestígio (Engenharia Elétrica) na UFMG, cursou mestrado e é engenheiro de uma grande empresa. Os autores apontam o desconforto do engenheiro em sua relação com a cultura legítima, o que os faz levantar a hipótese de que, "mesmo associada à posse de um elevado capital escolar não proporciona, necessariamente, à médio prazo, a incorporação pelos atores de origem popular da 'cultura legítima' ou da 'cultura erudita" (OLIVEIRA; PORTES, 2014, p. 1153). Assim como verificado por Lahire (1997) e Bourdieu e Champagne (1998), o sucesso escolar do pesquisado "fez surgir um distanciamento entre ele e seus familiares" (OLIVEIRA; PORTES, 2014, p. 1158).

\section{Comparativos entre trajetórias escolares de diferentes classes sociais}

Presta e Almeida (2008) analisaram as disposições quanto ao futuro de 14 adolescentes e suas famílias, pertencentes a diferentes grupos sociais. As autoras destacam que essas disposições são tributárias: do sentido da trajetória social do grupo familiar (ascendente ou descendente); da estrutura dos patrimônios, material e simbólico, das famílias, bem como a aceitação deles por parte dos jovens; e do veredito escolar sobre o desempenho dos jovens que determinam a forma como esse patrimônio é investido. Elas apontam para um ajustamento claro entre as disposições do grupo e 
suas chances de concretizá-las. Porém percebem que, para todos os grupos sociais, "[...] as ambições dos alunos só deixam de se correlacionar perfeitamente com a posição de suas famílias quando a escola acena num sentido diferente daquele que é esperado" (PRESTA; ALMEIDA, 2008, p. 420).

Retomando a questão dos planos em relação ao ensino superior, analisada por D’Ávila (1998), Portes (2000) e Viana (2000) na análise de trajetórias de alunos da camada popular, Presta e Almeida (2008) confirmam a percepção de que grupos menos favorecidos, independentemente de seu desempenho escolar, apresentam planos abstratos de acesso ao ensino superior e acrescentam a percepção sobre a existência de planos detalhados em alunos das camadas médias.

Muzzeti (2010) também comparou estratégias escolares de 6 alunas da camada média e 6 alunas da camada popular que frequentam o ensino superior no Campus de Araraquara da Universidade Estadual Paulista. Ela percebeu que todas mantinham uma relação tensa e insegura com o universo escolar, atribuído ao baixo capital cultural, pois seu habitus primário não incluía o consumo simbólico de práticas culturais legítimas. Quanto às alunas da camada média, filhas de pequenos comerciantes ou empresários, a pesquisa revelou que o ensino superior representava uma estratégia de reconversão. Na camada popular, a autora destacou que a universidade representou uma vitória social, uma estratégia de ascensão por parte dessas jovens, consideradas "eleitas".

Em estudos anteriores, Muzzeti $(1992,1997)$ enfocou o Curso Normal do Colégio Estadual e Escola Normal Dr. Álvaro Guião, da cidade de São Carlos, tendo analisado as trajetórias escolares das formandas do curso na década de 1940, incluindo alunas da camada privilegiada, média e popular. Muzzeti (1992) percebeu que o capital cultural herdado do meio familiar exerceu grande influência nas trajetórias escolares dessas alunas, tendo como base o ethos de classe, ou seja, a apreensão pelos pais do futuro escolar possível para suas filhas. Ela destaca ainda que o curso teve significados diferentes para cada classe: para as alunas da camada privilegiada representou uma vantagem a mais no mercado matrimonial; para as alunas da camada média significou um meio de vida, profissão, para manter o "status" de classe média; e para as alunas da camada popular representou ascensão social e alternativa ao trabalho manual. Em trabalho posterior, Muzzeti (1997) analisou a relação das disposições assimiladas pelas alunas no curso e sua influência no mercado matrimonial.

Nogueira (1991) identificou elementos característicos da relação entre diferentes classes sociais, considerando suas diferenças internas, e a escola, através de trajetórias 
escolares e estratégias culturais. Em resumo, as classes populares são marcadas por uma relação contraditória, pois ao mesmo tempo em que expressa sentimento de rejeição e distanciamento em relação à escola, depositam nela expectativas de promoção social. As camadas médias são marcadas pelo malthusianismo e ascetismo, que caracterizam toda a conduta social desse grupo. Quanto às elites, a autora destaca a desenvoltura e confiança própria desse grupo em relação à escola.

Encontramos também um trabalho específico sobre a questão do gênero nas trajetórias escolares, que não tinha como base os estudos de Bourdieu. Souza (2007) enfocou as práticas familiares e escolares a partir de relações de gênero de alunos das séries iniciais. A autora destacou uma mudança histórica que levou a um progresso mais rápido das meninas na alfabetização e uma quantidade maior de meninos com baixo desempenho escolar; o desempenho também é diferente em relação às disciplinas, sendo os meninos melhores em matemática e as meninas em português. A partir de entrevistas com 4 professoras do ensino fundamental, a autora observou que o modelo de masculinidade parece fomentar a indisciplina dos meninos, dificultando sua trajetória. Esse processo parece ser suportado pelas famílias. Por outro lado, as meninas seriam mais "quietas" e "boazinhas", ou seja, menos indisciplinadas, e isso facilitaria seu desempenho. Bourdieu aponta para essa "docilidade" feminina e consequente melhor desempenho escolar em entrevistas reunidas no documentário "A sociologia é um esporte de combate", dirigido por Pierre Carles (2001).

Em pesquisa realizada com 8 estudantes do curso de Pedagogia de uma instituição pública paulista, Suficier (2013) constata que o grupo possui uma relativa heterogeneidade em sua origem social (filhos de profissionais liberais com formação superior, de técnicos de nível médio e de profissionais com baixa qualificação e escolarização). Para o autor, é possível vislumbrar uma certa proximidade no volume de capital cultural incorporado pelos familiares das entrevistadas. Tal constatação advém da relação estabelecida pelos familiares das estudantes com as práticas e os bens culturais e a própria escolha do curso superior.

\section{Considerações finais}

De modo geral, as pesquisas analisadas apontam para fatores que devem ser considerados nas análises de trajetórias escolares e que permitem explicar o sucesso ou o fracasso escolar, mas que não devem ser considerados isoladamente. Entre eles 
prevalecem o patrimônio da família (capital cultural, econômico e social), bem como a incorporação dos capitais herdados por parte dos alunos, que não pode ser entendida como automática; a trajetória ascendente ou descendente das famílias; e o veredicto escolar.

Com relação aos procedimentos metodológicos das pesquisas, observamos que a maioria recorreu a entrevistas com os estudantes (Piotto, 2008; Nogueira e Pereira, 2010; Pereira, 2010) e, em algumas pesquisas, seus pais de forma prevista (D’Ávila, 1998; Presta e Almeida, 2008) ou acidental (Portes, 2000). Em casos envolvendo crianças e adolescentes nem sempre o estudante foi consultado (Presta e Almeida, 2008). Ao invés da entrevista, uma pesquisa adotou o questionário (Lelis, 2005), e em alguns casos ele serviu como complemento às entrevistas (Nogueira e Pereira, 2010). Sobre as opções metodológicas, Brandão (2000) aponta para a dificuldade na definição da metodologia adequada para cada pesquisa e defende que "[...] a questão está em ser capaz de selecionar os instrumentos da pesquisa em consonância com os problemas que se deseja investigar” (BRANDÃO, 2000, p. 173). Encontramos em Nogueira (2002) uma consideração sobre a amostra adotada na pesquisa, que acreditamos ser extensiva a todos os trabalhos. A autora ressalta que a “[...] amostra não tem pretensão de representatividade quantitativa, nem de dar conta de toda diversidade interna de um grupo social, o que não retira seu significado qualitativo" (NOGUEIRA, 2002, p. 51).

Podemos verificar que o referencial teórico e metodológico utilizado nas pesquisas analisadas baseia-se, principalmente, no corpus conceitual desenvolvido por Bourdieu, conforme já apontado por Paixão e Zago (2007) e as recentes contribuições de Lahire.

\section{REFERENCIAS}

ALMEIDA, A. M. F.; NOGUEIRA, M. A. (Org.). A escolarização das elites: um panorama internacional da pesquisa. Petrópolis: Vozes, 2002.

ALMEIDA, A. Ultrapassando o pai: herança cultural restrita e competência escolar. In: NOGUEIRA, M. A.; ROMANELLI, G.; ZAGO, N. (Org.). Família \& Escola: trajetórias de escolarização em camadas médias e populares. p. 83-97. Petrópolis: Vozes, 2000.

BOURDIEU, P. Futuro de classe e causalidade do provável. In: NOGUEIRA, M. A. e CATANI, A. (Org.). Escritos de educação. p. 83-126. Petrópolis: Vozes, 1998. 
BOURDIEU, P.; CHAMPAGNE, P. Os excluídos do interior. In: NOGUEIRA, M. A. e CATANI, A. (Org.). Escritos de educação. p. 218-227. Petrópolis: Vozes, 1998.

BOURDIEU, P.; PASSERON, J-C. La Reproduction: Éléments pour une théorie du système d'enseignement. Paris: Minuit, 1970.

BOURDIEU, P.; PASSERON, J-C. Les héritiers: les étudiants et la culture. Paris: Minuit, 1964.

BRANDÃO, Z. Entre questionários e entrevistas. In: NOGUEIRA, M. A.; ROMANELLI, G.; ZAGO, N. (Org.). Família \& Escola: trajetórias de escolarização em camadas médias e populares. p. 173-183. Petrópolis: Vozes, 2000.

CARLES, P. La sociologie est un sport de combat. França: Cara M.: 2h26 p. 2001

D'ÁVILA, J. L. P. Trajetória escolar: investimento familiar e determinação de classe. Educ. Soc., Campinas, v. 19, n. 26, p. 31-63, abr. 1998.

LAHIRE, B. Sucesso escolar nos meios populares: as razões do improvável. São Paulo: Ática, 1997.

LELIS, I. O significado da experiência escolar para segmentos das camadas médias. Cad. Pesqui., São Paulo, v. 35, n. 125, p. 137-160, maio/ago. 2005.

MASSI, L.; VILLANI, A.; MUZZETI, L. R. Trajetórias escolares de ingressantes do curso de licenciatura em Química de uma universidade particular paulista. VII Encontro Nacional de Pesquisadores em Educação em Ciências. Florianópolis: ABRAPEC, p. 1-12, 2009.

MASSI, L.; VILLANI, A.; MUZZETI, L. R. Análise comparativa de perfis e histórias de escolarização de licenciandos em Química de universidade pública e particular. IX Colóquio sobre questões curriculares e V Colóquio Luso Brasileiro. n. 9, 2010. Atas... Porto: Universidade do Porto, 2010. p. 5472-5483, 2010.

MUZZETI, L. R. A pluralidade das estratégias de reprodução: a luta pela longevidade escolar no espaço social universitário. In: SOUZA, C. B. G.; RIBEIRO, P. R. M. (Org.). Desafios educacionais para o século XXI: Contribuições dos contextos espanhol e brasileiro. Araraquara: Laboratório Editorial da Faculdade de Ciências e Letras UNESP, 2010.

MUZZETI, L. R. Trajetória social, dote escolar e mercado matrimonial: um estudo de normalistas formadas em São Carlos nos anos 40. 1997. 174p. Tese (Doutorado em Educação), Universidade Federal de São Carlos, UFSCAR, São Carlos, 1997.

MUZZETI, L. R. Trajetórias escolares de professoras primárias formadas em São Carlos nos anos 40. 1992. Dissertação (Mestrado em Educação). Universidade Federal de São Carlos, UFSCAR, São Carlos, 1992.

NOGUEIRA, C. M. M. Dilemas na análise sociológica de um momento crucial das trajetórias escolares: o processo de escolha do curso superior. 2004. 396p. Tese 
(Doutorado em Educação). Universidade Federal de Minas Gerais, UFMG, Belo Horizonte, 2004.

NOGUEIRA, C. M. M.; PEREIRA, F. G. O gosto e as condições de sua realização: a escolha por pedagogia entre estudantes com perfil social e escolar mais elevado. Educ. Rev., Belo Horizonte, v. 26, n. 3, p. 15-38, dez. 2010.

NOGUEIRA, M. A. Estratégias de escolarização em famílias de empresários. In: ALMEIDA, A. M. F.; NOGUEIRA, M. A. (Org.). A escolarização das elites: um panorama internacional da pesquisa. p. 49-65. Rio de Janeiro: Vozes, 2002.

NOGUEIRA, M. A. Família e escola na contemporaneidade: os meandros de uma relação. Educ. Real., Porto Alegre, v. 31, n. 2, p. 155-170, jul./dez. 2006.

NOGUEIRA, M. A. Favorecimento econômico e excelência escolar: um mito em questão. Rev. Bras. Educ., Rio de Janeiro, n. 26, p. 133-144, ago. 2004.

NOGUEIRA, M. A. Trajetórias escolares, estratégias culturais e classes sociais: notas em vista da construção do objeto de pesquisa. Teoria e Educação, Porto Alegre, v. 3, n. 3, p. 89-112, 1991.

NOGUEIRA, M. A. A construção da excelência escolar: um estudo de trajetórias feito com estudantes universitários provenientes das camadas médias intelectualizadas. In: NOGUEIRA, M. A.; ROMANELLI, G.; ZAGO, N. (Org.). Família \& Escola: trajetórias de escolarização em camadas médias e populares. p.127-154. Petrópolis: Vozes, 2000.

NOGUEIRA, M. A. Classes médias e escola: novas perspectivas de análise. Currículo sem Fronteiras, v. 10, n. 1, p. 213-231, jan./jun. 2010.

NOGUEIRA, M. A. Famílias de camadas médias e a escola: bases preliminares para um objeto em construção. Educ. Real., Porto Alegre, v. 20, n. 1, p. 9-25, jul./dez. 1995.

OLIVEIRA, E.; ALVARENGA, M. Juventudes e escolarização: Trajetórias escolares de jovens em espaço social de periferia urbana. VIII Jornadas de Sociología de la UNLP, 3 al 5 de diciembre de 2014, Ensenada, Argentina. En Memoria Académica, 2014. Disponível em:

<http://www.memoria.fahce.unlp.edu.ar/trab_eventos/ev.4395/ev.4395.pdf>. Acesso em: 22 nov. 2016.

OLIVEIRA, L. F.; PORTES, É. A. Ascensão e distanciamento na trajetória social, escolar e profissional de um jovem das camadas populares. Perspectiva, Florianópolis, v. 32, n. 3, p. 1145-1164, jun. 2014.

PAIXÃO, L. P.; ZAGO, N. (org.). Sociologia da educação: pesquisa e realidade brasileira. Petrópolis: Vozes, 2007.

PIOTTO, D. C. Trajetórias escolares prolongadas nas camadas populares. Cad. Pesqui., São Paulo, v. 38, n. 135, p. 701-727, set./dez. 2008. 
PORTES, É. A. O trabalho escolar das famílias populares. In: NOGUEIRA, M. A.; ROMANELLI, G.; ZAGO, N. (Org.). Família \& Escola: trajetórias de escolarização em camadas médias e populares. p.63-80. Petrópolis: Vozes, 2000.

\section{PORTES, É. A. Trajetórias escolares e vida acadêmica do estudante pobre da}

UFMG: um estudo a partir de cinco casos. 2001. 272p. Tese (Doutorado em Educação). Faculdade de Educação, Universidade Federal de Minas Gerais, Belo Horizonte, 2001.

PRADO, C. L. Em busca do primeiro mundo: intercâmbios culturais como estratégias educativas familiares. In: NOGUEIRA, M. A.; ROMANELLI, G.; ZAGO, N. (Org.). Família \& Escola: trajetórias de escolarização em camadas médias e populares. p.157170. Petrópolis: Vozes, 2000.

PRESTA, S.; ALMEIDA, A. M. F. Fronteiras imaginadas: experiências educativas e construção das disposições quanto ao futuro por jovens dos grupos populares e médios. Educ. Soc., Campinas, v. 29, n. 103, p. 401-424, ago. 2008.

ROCHEX, J-I. Le sens de l'experience scolaire: entre activité et subjectivité. Paris: Presses Universitaires de France, 1995.

ROMANELLI, G. Famílias de camadas médias e escolarização superior dos filhos: o estudante-trabalhador. In: NOGUEIRA, M. A.; ROMANELLI, G.; ZAGO, N. (Org.). Família \& Escola: trajetórias de escolarização em camadas médias e populares. p. 101123. Petrópolis: Vozes, 2000.

ROMANELLI, G. O significado da educação superior para duas gerações de famílias de camadas médias. Revista Brasileira de Estudos Pedagógicos, Brasília, v. 76, n. 184, p. 445-476, 1995.

ROMANELLI, G.; NOGUEIRA, M. A.; ZAGO, N. (Org.). Família \& Escola: novas perspectivas de análise. Petrópolis: Vozes, 2013.

SANTOS, L. L. C. P.; DIAS, R. L. C. Trajetórias escolares e prática profissional de docentes das camadas populares. Rev. Bras. Educ., Rio de Janeiro, v. 18, n. 52, p. 4964, mar. 2013.

SETTON, M. D. G. J. A divisão interna do campo universitário: uma tentativa de classificação. Revista Brasileira de Estudos Pedagógicos, Brasília, v. 80, n. 196, p. 451-471, 1999.

SETTON, M. D. G. J. Família, escola e mídia: um campo com novas configurações. Educ. Pesqui., São Paulo, v. 28, n. 1, p. 107-116, jan. /jun. 2002.

SOUZA, F. C. Desvendando práticas familiares e escolares a partir das relações de gênero: uma reflexão sobre a educação de meninos e meninas. 2007. 221p. Tese (Doutorado em Educação Escolar). Faculdade de Ciências e Letras do Campus de Araraquara, Universidade Estadual Paulista, Araraquara, 2007.

SOUZA, P. R. A universidade e a crise da educação. Revista USP, São Paulo, n. 8, p. 27-32, 1990-1991. 
SUFICIER, D. M. Retratos sociológicos de estudantes de Pedagogia: o caso da FCL/Ar. Araraquara, UNESP-FCLAR, 2013. Dissertação (Mestrado) - Programa de Pós-Graduação em Educação Escolar, Universidade Estadual Julio de Mesquita, 2013.

VIANA, M. J. B. Longevidade escolar em famílias de camadas populares: algumas condições de possibilidade. 1998. 266 (Doutorado). Faculdade de Educação, Universidade Federal de Minas Gerais, Belo Horizonte.

VIANA, M. J. B. Longevidade escolar em famílias de camadas populares: algumas condições de possibilidade. In: NOGUEIRA, M. A.; ROMANELLI, G.; ZAGO, N. (Org.). Família \& Escola: trajetórias de escolarização em camadas médias e populares. p. 47-80. Petrópolis: Vozes, 2000.

ZAGO, N. Processos de escolarização nos meios populares: as contradições da obrigatoriedade escolar. In: NOGUEIRA, M. A.; ROMANELLI, G.; ZAGO, N. (Org.). Família \& Escola: Trajetórias de escolarização em camadas médias e populares. p. 1943. Petrópolis: Vozes, 2000.

ZAGO, N. Do acesso à permanência no ensino superior: percursos de estudantes universitários de camadas populares. Rev. Bras. Educ., Rio de Janeiro, v. 11, n. 32, p. 226-370, ago. 2006.

\section{Como referenciar este artigo}

MASSI, Luciana.; MUZZETI, Luci Regina.; SUFICIER, Darbi Masson. A pesquisa sobre trajetórias escolares no Brasil. Revista Ibero-Americana de Estudos em Educação, Araraquara, v. 11, n. 3, p. 1854-1873, jul-set/2017. Disponível em: <http://dx.doi.org/10.21723/riaee.v12.n.3.2017.10364>. E-ISSN: 1982-5587.

Submetido em: 01/05/2017

Aprovação final em: 01/09/2017 